\title{
ANÁLISE DAS COMPONENTES HÍDRICAS, PRECIPITAÇÃO, EVAPOTRANSPIRAÇÃO E UMIDADE NA SUPERFÍCIE DO SOLO REPRESENTADAS PELO MODELO CLIMÁTICO REGIONAL REGCM3, PARA UMA REGIÃO DE CULTIVO DE SOJA
}

\author{
Viviane S. Guerra ${ }^{1}$, Virnei S. Moreira ${ }^{2}$, Diego Pedroso ${ }^{1}$, Débora R. Robert ${ }^{1}$, \\ Simone E. T. Ferraz ${ }^{1}$, Adriano Battisti ${ }^{1}$ \\ ${ }^{1}$ Universidade Federal de Santa Maria - UFSM -Santa Maria - RS \\ ${ }^{2}$ Universidade Federal do Pampa, UNIPAMPA, Itaqui - RS
}

Resumo: Este trabalho tem por finalidade testar as componentes do Balanço Hídrico utilizando o modelo regional RegCM3 para uma região de cultivo de soja.

Abstract: This study aims to test the components of the water balance using the RegCM3 regional model for a region of soybean cultivation.

\section{INTRODUÇÃO}

As formas de manejo do solo e a produtividade de uma região dependem da variabilidade climática e o do regime de precipitação. A disponibilidade hídrica varia com as fases de desenvolvimento da planta. Uma das principais variáveis que determina as necessidades hídricas de uma cultura é a perda de água por evapotranspiração que é composta pelas perdas por evaporação da água do solo nos processos metabólicos de desenvolvimento da planta e pela transpiração da folhagem. Dessa forma esse trabalho tem por objetivo analisar o comportamento das componentes hídricas, Precipitação, Evapotranspiração (ET) e a Umidade Superficial no Solo (USS), simuladas pelo modelo climático RegCM3 em relação as medidas no sítio experimental de Cruz Alta no estado do RS.

\section{DESENVOLVIMENTO}

Dados e Metodologia: Os dados de condição de contorno do modelo regional RegCM foram obtidos da Reanálise I do NCEP, de dezembro de 2009 a abril de 2010.

Para descrever os processos de interação solo-planta-atmosfera, foi utilizado o esquema BATS (Dickinson et al. 1993). BATS é um esquema que serve para descrever o papel da vegetação em interação com o solo nas trocas turbulentas, energia e vapor d'água entre superfície e atmosfera. O esquema de cumulus disponível no RegCM3 utilizado neste trabalho é o Grell (Grell, 1993) com fechamento - Arakawa-Schubert.

A evapotranspiração experimental foi estimada pelo método covariância dos vórtices obtidos de dados coletados por uma torre micrometeorologia instaladas em Cruz Alta - RS $\left(28^{\circ} 36^{\prime} \mathrm{S}, 5^{\circ} 40^{\prime} \mathrm{O}\right)$, na CCGL TEC/ FUNDACEP. O ciclo da soja no sitio experimental de Cruz Alta avaliada neste trabalho iniciou no dia 19 de Dezembro de 2009 com a emergência da planta e terminou no dia 28 de Abril de 2010, totalizando 131 dias, do Dia Após Emergência (DAE) à colheita.

Resultados: É possível perceber que o modelo simula o padrão de distribuição de chuva durante o plantio para a região de Cruz Alta como mostra a Figura 1. Asafrade sojafoi caracterizadapor chuvas regulares até em torno do $65^{\circ}$ DAE, após esta data dois periodos foram marcados por menos chuvas entre o $65^{\circ}$ DAE e $100^{\circ}$ DAE para os dados observados 
(Figura 2(a)). O modelo superestima no incio do ciclo e subestima no final do ciclo próximo ao $120^{\circ}$ dia. Avalia-se então, que o modelo acompanha os dados observados, exceto para grandes volumes de chuvas ou estiagens mais severas. A grande variabilidade de evapotranspiração está associada com as chuvas e fases de desenvolvimento da cultura de modo que ET segue a curva de aumento e decaimento da precipitação (Figura 2 (a) e (b)), bem como o ciclo e crescimento e maturação da planta. O Modelo acompanha a tendência dos dados observados, porém existe uma defasagem em relação ao decaimento da evapotranspiração. Nota-se que a partir do $120^{\circ}$ DAE começa a normalizar as curvas para o observado e simulado devido principalmente à regularização da precipitação.

A umidade na superfície do solo retrata muito sobre a necessidade da planta em relação ao que necessitará de água no decorrer do ciclo. Para os valores simulados o solo está absorvendo mais água no período de estiagem do que em relação ao observado, podemos notar essa ocorrência entre o $100^{\circ} \mathrm{DAE}$ e o $120^{\circ} \mathrm{DAE}$, pois a curva torna-se mais abrupta e não tão suave como o observado.

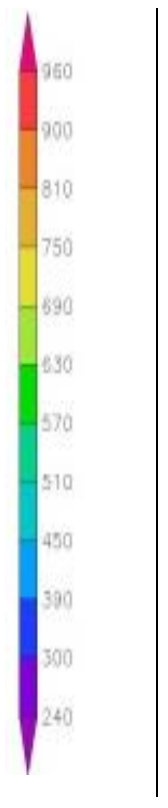

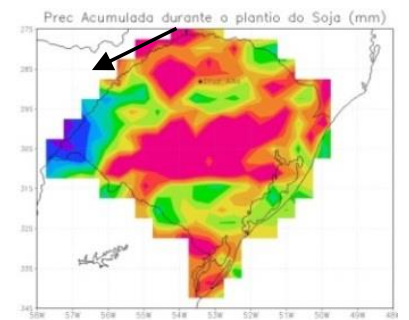

(a)

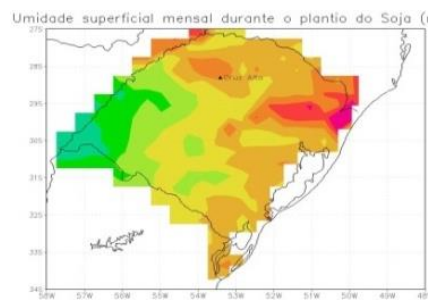

(c)

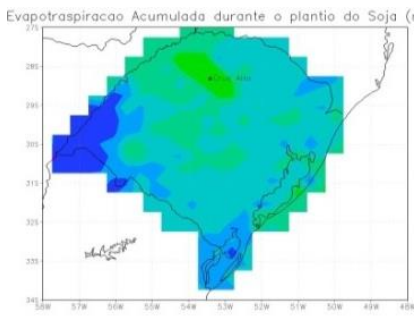

(b)

Figura 1: (a) Precipitação acumulada $(\mathrm{mm})$, durante o ciclo da soja. (b) Evapotranspiração acumulada (mm). (c) USS média mensal $(\mathrm{mm})$. A seta em preto aponta para a região de estudo (Cruz Alta, $\mathrm{RS})$.

Tabela 1: Índices estatísticos foram calculados para as componentes hidrológicas com um nível de significância de $99 \%$.

\begin{tabular}{|c|c|c|c|c|}
\hline & $\begin{array}{c}\text { Acumulado( } \\
\mathrm{mm})\end{array}$ & $\begin{array}{c}\text { Média } \\
\text { diária(mm) }\end{array}$ & $\begin{array}{c}\text { RMSE } \\
(\mathrm{mm})\end{array}$ & $\mathrm{r}^{2}$ \\
\hline Precipitação Observada & 653,50 & 5,11 & & \\
\hline Precipitação Simulada & 511,60 & 4,00 & 12,5 & 0,11 \\
\hline ET Observada & 410,88 & 3,20 & & \\
\hline ET Simulada & 487,00 & 3,80 & 1,90 & 0,20 \\
\hline USS Observada (mensal) & 589,30 & 35,19 & & \\
\hline USS Simulada (mensal) & 900,75 & 23,02 & 13,20 & 0,35 \\
\hline
\end{tabular}




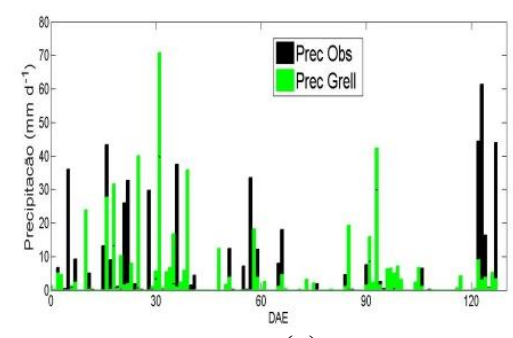

(a)

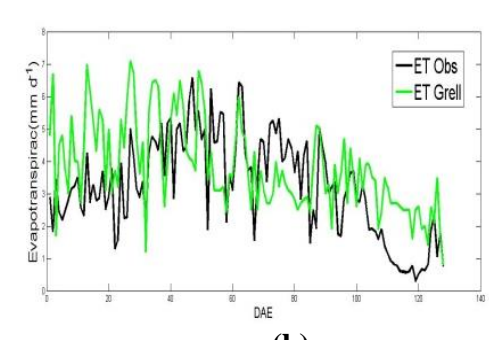

(b)

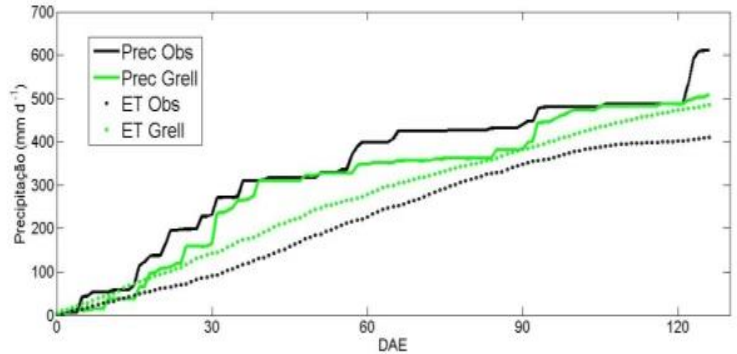

(c)

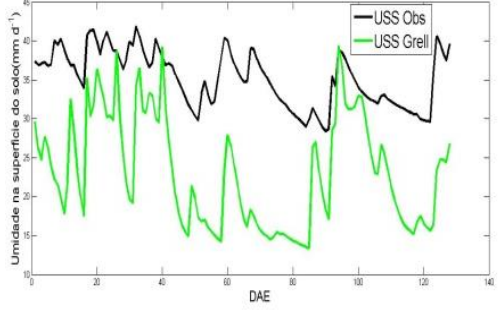

(d)
Figura 2: (a) Precipitação acumulada diária durante o ciclo na soja, em preto a observada e em verde a simulada. (b) ET (preto a observada, verde a simulada). (c) ET e Precipitação acumulada durante o plantio. (d) USS a $10 \mathrm{~cm}$.

\section{CONCLUSÃO}

De modo geral o modelo tanto para a Precipitação quanto para a ET e para USS consegue descrever o padrão de distribuição dessas componentes, porém mostra certa dificuldade em captar períodos extremos, como os mais secos e mais úmidos.

\section{REFERÊNCIAS}

ARAKAWA, A. and W.H. SCHUBERT, 1974: Interaction of a cumulus cloud ensemble with the largescale environment, Part I. Journal of the Atmospheric Science, 31, 674-701.

DICKINSON, R. E.: Biosphere-atmosphere transfer scheme (BATS) version 1E as coupled to the NCAR Community Climate Model. Boulder, Colorado: Tech Note NCAR/TN-387, 72pp., 1993.

GRELL, G.A. 1993: Prognostic evaluation of assumptions used by cumulus parameterizations. Monthly Weather Review, 121, 764-787. 